\title{
DOMINANSI GULMA INVASIF PADA BEBERAPA TIPE PEMANFAATAN LAHAN DI KECAMATAN SAWANG KABUPATEN ACEH UTARA
}

\section{DOMINANCE OF INVASIVE WEEDS IN VARIOUS LAND USES IN SAWANG DISTRICT, ACEH UTARA REGENCY}

\author{
Nanda Firmansyah $^{1}$, Khusrizal $^{2}$, Rd Selvy Handayani ${ }^{2}$, Maisura ${ }^{2}$ dan Baidhawi $^{2 *}$ ) \\ ${ }^{1}$ Mahasiswa Program Studi Magister Agroekoteknologi Fakultas Pertanian Universitas Malikussaleh \\ Kampus Reuleut, Aceh Utara, Aceh, Indonesia \\ ${ }^{2}$ Program Studi Magister Agroekoteknologi Fakultas Pertanian Universitas Malikussaleh \\ Kampus Reuleut, Aceh Utara, Aceh, Indonesia \\ *Corresponding author: baidhawi@unimal.ac.id
}

\begin{abstract}
ABSTRAK
Gulma invasif mampu menginvasi suatu lahan apabila memiliki kemampuan dominansi terhadap tumbuhan asli. Proses invasif diawali dari kehadiran gulma invasif disuatu areal lahan hingga terjadinya dominansi. Penelitian ini bertujuan menghitung dominansi spesies gulma invasif pada beberapa tipe pemanfaatan lahan di Kecamatan Sawang Kabupaten Aceh Utara dengan metode survei dan purposive sampling, plot bersarang dibuat sebanyak 24 plot untuk masing-masing tingkatan vegetasi gulma. Penelitian ini dilaksanakan pada beberapa tipe pemanfaatan lahan pertanian yang meliputi lahan tegalan/kebun, ladang/huma, perkebunan, hutan rakyat, padang rumput, sawah irigasi, sawah non irigasi dan tambak/kolam di Kecamatan Sawang Kabupaten Aceh Utara pada bula AprilJuni 2020. Setiap jenis gulma invasif yang dijumpai di dalam petak sampling diambil foto, dicocokkan morfologinya berdasarkan buku identifikasi gulma kemudian dihitung dominansinya. Parameter penelitian yaitu komposisi gulma invasif pada tingkat vegetasi dan dominansi gulma invasif pada setiap tipe pemanfaatan lahan. Hasil penelitian menunjukkan bahwa pada lahan tegalan/kebun didominasi oleh spesies Axonopus compressus $(27,57 \%)$, ladang atau huma didominasi oleh gulma Rhynchospora colorata (37,94\%), lahan perkebunan didominasi oleh gulma Ageratina adenophora $(65,90 \%)$, hutan rakyat hanya ditemukan satu jenis gulma yaitu Digitaria fuscescens $(68,75 \%)$, areal padang rumput didominasi oleh gulma Dactyloctenium aegyptium (33,71\%), lahan sawah irigasi didominasi oleh gulma Panicum maximum (22,97\%), sawah non irigasi didominasi oleh gulma Mimosa pudica (22,02\%), dan lahan tambak/kolam didominasi oleh gulma Eleusine indica $(54,17 \%)$. Penelitian ini diharapkan dapat memberikan informasi tentang kemampuan dominansi gulma invasif pada setiap tipe pemanfaatan lahan di Kecamatan Sawang Kabupaten Aceh Utara.
\end{abstract}

Kata kunci: Dominansi, gulma invasif, tipe lahan.

\begin{abstract}
Invasive weeds are alien species that show a tendency to spread out of control. They compete vigorously with native plants frequently dominate and replace them. The purpose of this research was to determine the dominant weeds in several lands uses such as dry land/garden, field, plantation, forest, grassland, irrigated rice field, non-irrigated rice field,
\end{abstract}


and pond in Sawang district, Aceh Utara Regency from April to June 2020, using survey and purposive sampling methods. Independent 24 plots were prepared for screening weed vegetation. Each invasive found was captured using a camera and was identified and calculated for its dominance. Variables observed were invasive weeds in vegetation and several land uses. The results showed that dry land/garden was dominated by species Axonopus compressus (27.57\%), the field by species Rhynchospora colorata (37.94\%), plantation by species Ageratina adenophora (65.90\%). Surprisingly, forest was dominated by one species only, Digitaria fuscescens (68.75\%). In grassland was occupied by Dactyloctenium aegyptium (33.71\%), irrigated rice field by species Panicum maximum (22.97\%), the non-irrigated field with Mimosa pudica (22.02\%), and the pond was abundant with Eleusine indica (54.17\%). This research was expected to give useful information for farmers about the dominance of invasive weeds in various land uses in Sawang District, Aceh Utara Regency.

Kata kunci; Dominance, Invasive weeds, Land types.

\section{PENDAHULUAN}

Invasi merupakan pergerakan suatu spesies dari suatu area menuju ke area lain dengan kondisi berbeda kemudian secara perlahan mengokupasi habitat barunya. Suatu spesies introduktif dapat menjadi invasif jika spesies ini mampu berkompetisi dan mengalahkan spesies asli dalam memperebutkan sumber daya seperti nutrisi, cahaya, ruang, air dan lainnya. Spesies gulma dikatakan invasif apabila spesies tersebut mampu menginvasi lingkungan dan memiliki kemampuan dominansi pada_suatu areal lahan terhadap tumbuhan asli. Pada dasarnya proses invasi dari spesies gulma dapat dibagi menjadi tiga proses yaitu introduksi, kolonisasi dan dominansi. Dominansi merupakan jumlah luas area yang ditumbuhi oleh suatu jenis gulma. Dominansi sangat erat hubungannya dengan invasi. Tjitrosoedirdjo (2015) menyatakan bahwa invasi adalah suatu sifat yang menggambarkan kinerja suatu spesies gulma yang menjadi dominan serta mengancam ekosistem, habitat dan spesies yang terdapat disuatu lahan.

Proses invasi terjadi secara bertahap diawali dari kehadiran spesies invasif di suatu areal lahan hingga terjadinya pengambil alihan lokasi baru. Gulma invasif mampu mendominasi areal tumbuhnya dengan sifat pertumbuhan gulma yang cepat, perakaran yang banyak dan rapat, menggunakan penyerbukan lokal sehingga mampu memproduksi biji, metode penyebaran biji efektif seperti buah yang disukai hewan atau biji yang ringan sehingga mudah dibawa angin, biji yang dihasilkan banyak sehingga cepat mendominasi areal dan memiliki senyawa alelopati yang dapat menghambat pertumbuhan jenis tumbuhan asli (Tjitrosoedirdjo, 2005)

Penggunaan lahan secara umum didefinisikan sebagai penggolongan penggunaan lahan yang dilakukan secara umum seperti pertanian tadah hujan, pertanian irigasi, padang rumput, kehutanan, atau daerah rekreasi. Kemampuan adaptasi yang besar dari gulma invasif menyebabkan gulma berkembang cepat dengan dominansi yang tinggi terhadap tumbuhan lainnya (tanaman asli) pada suatu kawasan yang relatif cukup luas dan kemudian berkembang menjadi spesies yang berbahaya pada kondisi lingkungan yang rusak atau berubah. Dalam habitat barunya mungkin hanya ada sedikit predator atau penyakit sehingga populasinya tumbuh tak terkendali dan tanaman asli tidak dapat berkompetisi dengan baik terhadap ruang dan makanan, sehingga terdesak bahkan dapat mengalami kepunahan (Pusat Litbang Hutan Tanaman Departemen Kehutanan, 2014).

Keberadaan gulma invasif ini 
disadari sebagai salah satu ancaman terbesar bagi keanekaragaman hayati. Dampak gulma yang bersifat invasif ini mampu merubah struktur dan komposisi spesies dalam ekosistem. Spesies lokal tidak mampu bersaing dan terancam punah. Secara ekonomi, dampak invasi gulma sangat signifikan, dalam bidang pertanian muncul berbagai jenis hama dan penyakit tanaman asing yang belum dikenal petani cara penanganannya, ekosistem air tercemar oleh berbagai gulma, yang akhirnya semua berujung pada peningkatan biaya pengendalian yang lebih tinggi. Oleh karena itu, seiring dengan meningkatnya penyebaran spesies invasif yang akan mengancam keragaman hayati, maka diperlukan kajian untuk menghitung dominansi yang ditimbulkan dari kehadiran gulma invasif.

Penelitian ini bertujuan untuk menghitung dominansi spesies gulma invasif pada beberapa tipe pemanfaatan lahan di Kecamatan Sawang Kabupaten Aceh Utara.

\section{METODE PENELITIAN}

untuk masing-masing tingkatan vegetasi gulma menggunakan metode plot bersarang yang diletakkan berdasarkan purposive sampling. Plot berukuran 10x10 meter digunakan untuk tingkat pohon (a), plot berukuran $5 \times 5$ meter untuk tingkat pancang (b) dan plot berukuran $2 \times 2$ meter untuk tingkat vegetasi dasar (c).

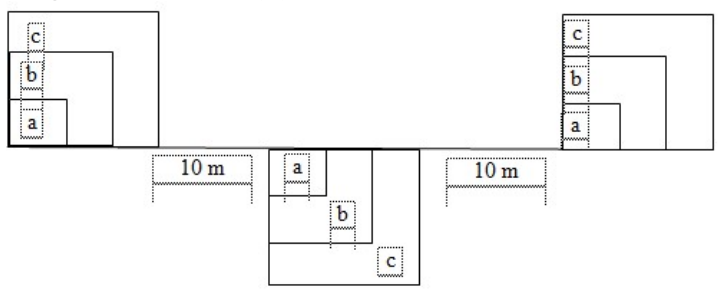

Gambar 1. Peletakan plot pengamatan

Setiap jenis gulma invasif yang dijumpai di dalam petak sampling diambil foto, dicatat ciri--ciri morfologinya kemudian dihitung dominansinya. Gulma invasif yang tidak diketahui jenisnya dan dikoleksi dalam bentuk herbarium untuk diidentifikasi di Laboratorium Agroeko-teknologi
Fakultas Pertanian Universitas Malikussaleh. Identifikasi jenis gulma invasif berpedoman pada buku "Guide Book to Invasive Alien Plant Species in Indonesia" (Setyawati et al., 2015). Wawancara dilakukan secara langsung dengan menanyai pejabat lembaga terkait, penyuluh pertanian dan petani sekitar lokasi pengamatan dilakukan untuk menggali informasi lebih lanjut tentang gulma invasif.

Untuk mengetahui dominansi gulma dihitung dengan menggunakan Summed Dominance Ratio (SDR) yang diperoleh dari hasil Nilai Penting (NP) dibagi 3. Sedangkan NP diperoleh melalui kerapatan relatif (KR), frekuensi relatif (FR) dan dominansi relatif (DR). SDR umum dipakai karena jumlahnya tidak pernah lebih dari 100\%, sehingga mudah untuk diinterpretasikan. Semakin tinggi nilai SDR jenis gulma, maka akan semakin tinggi pengaruh gulma tersebut dalam mendominasi suatu area dari jenis gulma lainnya.

Perhitungan parameter SDR gulma dilakukan dengan menggunakan persamaan menurut Tjitrosoedirdjo, et al (1984) sebagai berikut:

$$
\begin{aligned}
& E R(0)=\frac{\text { Kerapatan mutlak suatujenis }}{\text { Jumlah kerapatan mutlak semua jenis }}=\mathrm{x} 100 \% \\
& F R(\phi b)=\frac{\text { Nilan frekuensı mutlak suatu jenis }}{\text { Jumlah nilai trekuensi mutlaksemua jenis }} \\
& =\mathrm{x} 100 \% \mathrm{~W} \\
& D R((\phi))=\frac{\text { Nilai dominansi mutlak suatujenis }}{\text { Jumlah semua petak contohyang diambil }} \\
& =\mathrm{x} 10090
\end{aligned}
$$

\section{HASIL DAN PEMBAHASAN}

Berdasarkan data pada Tabel 1 menunjukkan bahwa tingkat pertumbuhan gulma invasif pada tingkatan semai lebih dominan dibandingkan dengan tingkat pertumbuhan pancang, bahkan pada tingkatan tiang/pohon tidak ditemukan gulma invasif pada setiap tipe pemanfaatan 
lahan di Kecamatan Sawang Kabupaten Aceh Utara.

Tabel 1. Komposisi vegetasi pada beberapa tipe pemanfaatan lahan di Kecamatan Sawang Kabupaten Aceh Utara.

\begin{tabular}{llccc}
\hline No & $\begin{array}{c}\text { Tingkat } \\
\text { Vegetasi }\end{array}$ & $\begin{array}{c}\text { Jumlah } \\
\text { Famili }\end{array}$ & $\begin{array}{c}\text { Jumlah } \\
\text { Spesies }\end{array}$ & $\begin{array}{c}\text { Jumlah } \\
\text { Individu }\end{array}$ \\
\hline 1. & Semai & 11 & 32 & 572 \\
2. & Pancang & 3 & 4 & 87 \\
3. & Tiang/ & 0 & 0 & 0 \\
\hline
\end{tabular}

Pada tingkat semai didapatkan 11 famili, 32 spesies dan 572 individu gulma, sedangkan pada tingkat pertumbuhan pancang terdapat 3 famili, 4 spesies dan 87 individu gulma. Jumlah spesies dan jumlah individu gulma invasif pada suatu lahan dipengaruhi oleh faktor lingkungan yaitu suhu, temperatur, kelembapan, tanah, ruang tumbuh dan cahaya (Moenandir, 2005). Hal ini juga didukung oleh pernyataan Lubis (2008) bahwa keberadaan gulma invasif akan berbeda pada setiap jenis lahan, hal ini tergantung pada lokasi, iklim dan cahaya.

Tabel 2.Nilai SDR gulma invasif pada beberapa tipe pemanfaatan lahan di Kecamatan Sawang Kabupaten Aceh Utara

\begin{tabular}{llc}
\hline $\begin{array}{c}\text { Tipe } \\
\text { Pemanfaa } \\
\text { tan Lahan }\end{array}$ & Spesies Gulma Invasif & $\begin{array}{c}\text { SDR } \\
(\%)\end{array}$ \\
\hline & Axonopus compressus & 27,57 \\
Tegalan/ & Paspalum conjugatum & 26,63 \\
Kebun & Phyllantus urinaria & 19,34 \\
& Chromoleana odorata & 15,13 \\
& Ludwigia octovalvis & 11,33 \\
\hline \multirow{3}{*}{ Ladang/ } & Rhynchospora colorata & 37,94 \\
Huma & Digitana longiflora & 16,61 \\
& Spigelia anthelmia & 16,32 \\
& Cyperus distans & 15,12 \\
\hline Perke- & Euphorbia heterophylla & 14,00 \\
\hline
\end{tabular}

\begin{tabular}{|c|c|c|}
\hline bunan & Heliotropium indicum & 34,10 \\
\hline $\begin{array}{l}\text { Hutan } \\
\text { Rakyat }\end{array}$ & Digitaria fuscescens & 68,75 \\
\hline \multirow{4}{*}{$\begin{array}{l}\text { Padang } \\
\text { Rumput }\end{array}$} & $\begin{array}{l}\text { Dactyloctenium } \\
\text { aegyptium }\end{array}$ & 33,71 \\
\hline & Agiratina riparia & 27,51 \\
\hline & Digitaria divaricatissima & 20,85 \\
\hline & Pennisetum purpureum & 17,92 \\
\hline \multirow{10}{*}{$\begin{array}{l}\text { Sawah } \\
\text { Irigasi }\end{array}$} & Panicum maximum & 22,97 \\
\hline & Fimbristylis alboviridis & 9,73 \\
\hline & Actinosarpus grossus & 9,73 \\
\hline & Sphagneticola trilobata & 8,29 \\
\hline & Cyperus rotundus & 7,92 \\
\hline & Spilanthes iabadicensis & 7,92 \\
\hline & Setaria pumila & 7,56 \\
\hline & Ruellia tuberosa & 7,20 \\
\hline & Spermacoce laevis & 6,84 \\
\hline & Hyptis capitata Jacq. & 6,84 \\
\hline $\begin{array}{l}\text { Tipe } \\
\text { Pemanfaat } \\
\text { an Lahan }\end{array}$ & Spesies Gulma Invasif & $\begin{array}{l}\text { SDR } \\
(\%)\end{array}$ \\
\hline \multirow{7}{*}{$\begin{array}{l}\text { Sawah Non } \\
\text { Irigasi }\end{array}$} & Mimosa pudica & 22,02 \\
\hline & Ageratum hostianum & 17,63 \\
\hline & Ludwigia perennis & 15,48 \\
\hline & Amarantus spinosus & 12,96 \\
\hline & Portulaca ioleracea & 12,96 \\
\hline & Rhynchospora corymbosa & 12,60 \\
\hline & Ageratum conyzoides & 6,36 \\
\hline Tambak/ & Eleusine indica & 54,17 \\
\hline Kolam & Jussiaea limifolia Vahl & 45,83 \\
\hline
\end{tabular}

Dari data di atas (Tabel 2) menunjukkan bahwa pada lahan tegalan/kebun gulma invasif yang mendominasi adalah spesies Axonopus compressus (SDR 27,57\%), kemampuan $A$. compressus mendominasi lahan tegalan/kebun sangat dipengaruhi oleh perkembangbiakan gulma yang begitu cepat, dimana gulma ini memiliki alat perkembangbiakan vegetatif (stolon) dan generatif (biji). Hal ini sesuai dengan pernyataan Bohari (2012) yaitu $A$. compressus berkembangbiak dengan cepat 
melalui biji atau dengan stolon, biji-bijinya mudah sekali menempel pada benda yang menyentuhnya, terutama dalam keadaan basah. Pada lahan ladang atau huma didominasi oleh gulma Rhynchospora colorata (SDR 37,94\%). Gulma ini mampu mendominasi areal ladang dikarenakan $R$. colorata memiliki kemampuan penguasaan ruang perakaran akibat struktur perakarannya yang lebat serta memiliki kemampuan tingkat konsumsi penyerapan air dan hara yang tinggi, dan ketika lahan tidak dilakukan pembudidayaan maka gulma ini mampu tumbuh dan berkembang dengan sangat baik. Pada lahan perkebunan didominansi oleh gulma Ageratina adenophora (SDR 65,90\%). Gulma ini berkembangbiak dengan biji dan stek batang, batang dapat menumbuhkan akar dan tumbuh setelah kontak dengan tanah, selain itu biji gulma bisa dengan mudah terbawa oleh angin atau air dan juga dapat melekat pada bagian tubuh hewan.

Pada lahan hutan rakyat hanya ditemukan satu jenis gulma yaitu Digitaria fuscescens dengan nilai dominansi 68,75\%. Areal padang rumput didominasi oleh gulma Dactyloctenium aegyptium (SDR 33,71\%). Gulma yang berasal dari golongan rumput ini mampu berkembangbiak dengan biji dan stolon dan lebih mudah tumbuh pada musim kemarau (Bohari, 2012). Jenis rumput yang mempunyai stolon mempunyai sifat lebih tahan defoliasi berat, cepat menutup tanah, dan lebih efektif menahan erosi. Pada lahan sawah irigasi ditemukan spesies gulma invasif paling banyak dengan gulma Panicum maximum yang paling mendominasi (SDR 22,97\%). Gulma ini mampu tumbuh dan menguasai areal lahan dengan cepat dikarenakan gulma ini mampu berkembangbiak secara apomiksis. Seperti yang dilaporkan oleh Savidan (1982) bahwa $P$. maximum bereproduksi dengan cara apomiksis fakultatif. Reproduksi secara apomiksis adalah reproduksi klonal dengan menggunakan biji, namun tanpa adanya kontribusi dari gamet jantan. Hal ini menyebabkan P.maximum mampu tumbuh dengan cepat dengan waktu berbunga 20 hari dan menghasilkan tanaman yang secara genetik identik dengan induknya (Polegri et al., 2010).

Pada lahan sawah non irigasi didominasi oleh gulma Mimosa pudica (SDR 22,02\%), M. pudica biasa tumbuh liar di tempat-tempat terbuka yang terkena sinar matahari. pada plot pengamatan sawah non irigasi meruapakan areal terbuka dan mendapatkan sinar matahari langsung. M. pudica berasal dari daerah subtropis dan tropis Amerika, yaitu dari timur laut Argentina dan tenggara Brazil hingga ke barat daya Meksiko. Diperkirakan tanaman ini masuk (diintroduksi) secara tidak sengaja ke kawasan Asia Tenggara pada abad ke 19. Di awal abad ke 20, spesies ini ditanam di perkebunan di Jawa dan Sumatra, dan sejak saat itu tersebar ke berbagai negara Asia Tenggara lainnya (Kurnia et al, 2014). Gulma ini memiliki daun tidak lengkap, bentuk daun memanjang, ujung daun runcing, pangkal daun rompang, tepi daun rata, pertulangan daun menyirip, daging daun seperti kertas dan permukaan daun licin mengkilat serta termasuk kedalam daun majemuk menyirip genap.

Pada lahan tambak/kolam didominasi oleh gulma Eleusine indica (SDR 54,17\%). Gulma ini mampu tumbuh dan berkembang pada tanah yang bersifat asam seperti halnya lahan tambak/kolam. E. indica merupakan spesies rumput yang tumbuh baik pada areal terbuka, kering, terganggu, dan tahan terhadap tanah asam yang mengandung asam sulfat (Biotrop 2008). E. indica berasal dari Australia. Spesies ini dikatakan invasif karena dapat tumbuh pada berbagai jenis tanah, membutuhkan cahaya matahari yang tinggi, tingkat reproduksi tinggi, memiliki propagul yang dapat bertahan hidup lebih dari satu tahun, memiliki tingkat penyebaran yang tinggi, toleran terhadap pengembalaan, dan kebakaran (CABI, 2014).

Tingginya aktivitas manusia seringkali memunculkan gangguan terhadap ekosistem, yaitu terbukanya 
vegetasi tumbuhan yang ada. Bukaan vegetasi ini akan menyediakan ruang kosong yang kemudian akan diinvasi oleh jenis gulma invasif yang memiliki pertumbuhan sangat cepat. Sifat mendominasi suatu spesies gulma tertentu dapat menimbulkan dampak buruk bagi ekosistem yang ditempati jenis tersebut.

\section{KESIMPULAN}

Terdapat dominansi gulma invasif pada beberapa tipe pemanfaatan lahan di Kecamatan Sawang Kabupaten Aceh Utara. Dominsi gulma invasif pada lahan sebagai berikut: pada lahan tegalan/kebun didominansi oleh Axonopus compressus, pada ladang/huma didominansi oleh Rhynchospora colorata, pada lahan perkebunan didominansi oleh Ageratina adenophora, dan pada lahan hutan rakyat didominansi oleh Digitaria fuscescens. Gulma padang rumput didominansi oleh Dactyloctenium aegyptium, lahan sawah irigasi didominansi oleh Panicum maximum, lahan sawah non irigasi didominansi oleh Mimosa pudica, dan lahan tambak/kolam didominansi oleh gulma Eleusine indica.

\section{DAFTAR PUSTAKA}

[BIOTROP] South East Asian Regional Centre for Tropical Biology. 2008. Invasive Alien Species. http://www.biotrop.org/database.php?a $\mathrm{ct}=$ dbias. diakses 17 Juli 2020.

Bohari M. 2012. Identifikasi Jenis-Jenis Poaceae di Area Kampus 2 Uin Alauddin. Jurusan Biologi Fakultas Sains dan Teknologi Universitas Islam Negeri Alauddin Makassar.

[CABI] Scientific Expertise to Solve Problems in Agriculture and The Environment. 2014. Eleusine indica. $\underline{\mathrm{h}}$ ttp://www.cabi.org/isc/datasheet/2067 5. Diakses pada 17 Juli 2020.

Kurnia, N., Jumadi, O., Hiola, F. Atlas Tumbuhan Sulawesi Selatan. 2014. Edisi Lab School UNM. Program Studi Biologi. Jurusan Biologi
Fakultas Matematika Dan Ilmu Pengetahuan Alam Universitas Negeri Makassar. 205 hal. ISBN 978-602-70469-0-0.

Lubis A.U. 2008. Tanaman Singkong (Manihot esculenta) di Indonesia. Edisi 2. Pusat Penelitian. Medan. Sumatera Utara.

Moenandir.J. 2005. Ilmu Gulma Dalam Sistem Pertanian. Jakarta: Rajawali Grafindo.

Polegri L, Calderini O, Arcioni S, Pupilli F. 2010. Specific expression of apomixis-linked alleles revealed by comparative transcriptomic analysis of sexual and apomictic Paspalum simplex Morong flowers. J Experiment Botany. 61:1869-1883.

Pusat Litbang Hutan Tanaman, Departemen Kehutanan. 2014. Potensi Invasif beberapa Jenis Acasia dan Eucalyptus di Indonesia. Departemen Kehutanan. Bogor.

Savidan, Y. H. 1982. Embryological analysis of facultative apomixis in Panicum maximum Jacq. Crop Science, 22(3): 467-469.

Setyawati T, Narulita S, Bahri I.P, Raharjo G.T. 2015. A Guide Book to Invasive Alien Plant Species in Indonesia. ISBN: 978-979-845266-6. Development and Innovation Agency. Ministry of Environment and Forestry.

Tjitrosoedirdjo, S., I. H. Utomo, dan J. Wiroatmodjo. 1984. Pengelolaan Gulma Di Perkebunan. Gramedia. Jakarta.

Tjitrosoedirdjo, S. S. 2005. Inventory of the invasive alien species in Indonesia. Biotropia, 25, 6773.

Tjiptrosoedirjo, S. 2015. Tumbuhan Invasif. Pelatihan ke III Pengelolaan Gulma dan Tumbuhan Invasif SEAMEO BIOTROP. Bogor. 